\title{
Training to Train Resident as A Clinical Teacher: Perception of the Participant Residents
}

\author{
Piryani Rano Mall*, Piryani Suneel ${ }^{2}$, Mishra Ravish ${ }^{3}$ and Poudel Rajesh ${ }^{4}$ \\ ${ }^{1}$ Professor of Internal Medicine and Chief Coordinator, Universal College of Medical Sciences, Nepal \\ ${ }^{2}$ Department of Community Health Sciences, Aga Khan University, Pakistan \\ ${ }^{3}$ Department of Oral and Maxillofacial Surgery, Universal College of Dental Surgery Bhairahawa, Nepal \\ ${ }^{4}$ Department of Surgery, Universal College of Medical Sciences, Nepal
}

*Corresponding author: Piryani Rano Mal, Professor of Internal Medicine and Chief Coordinator-Health Professions Training Committee, Universal College of Medical Sciences, Bhairahawa, Nepal.

To Cite This Article: Piryani Rano Mal. Training to Train Resident as A Clinical Teacher: Perception of the Participant Residents. Am J Biomed Sci \& Res. 2019 - 3(6). AJBSR.MS.ID.000724. DOI: 10.34297/AJBSR.2019.03.000724

Received: June 26, 2019 | Published: July 10, 2019

\begin{abstract}
Introduction: The residents have long been recognized as resource for clinical teaching to students, interns, junior residents. They need to train to become effective clinical teachers. That's why Universal College of Medical Sciences Bhairahawa, Nepal organized one day "Training to train resident as a clinical teacher". The objective this study was to take feedback of the participant residents and assess how they perceive the training at level-I of Kirkpatrick model of evaluation.

Methodology: Feedback of the participants of training was taken on the valid semi-structured questionnaire comprised of four parts: Part A-Demographic information, Part B-Overall feedback on training, Part C. Feedback on specific sessions and Part D- Feedback for the improvement. Data was analyzed using IBMS SPSS version 21.

Results: The participants rated training on scale 1-10 (1=poor, $10=$ excellent) for usefulness $9.21 \pm 1.05$, content $9.07 \pm 1.00$, relevance $9.29 \pm 0.82$, facilitation $9.50 \pm 0.85$, and overall $9.29 \pm 0.82$. They rated on specific session/s "knows about adult learning principles" $8.71 \pm 1.25$ and "learning domains" $8.93 \pm 1.41$ on scale $1-10$ (1=poor, $10=$ excellent), while on sessions "How to be an effective clinical teacher" $3.79 \pm 0.43$ and sub-session "How to plan a lesson for teaching" 3.79 \pm 0.43 rated on Likert Scale 1-4 (4=extremely important, 3=moderately important, 2=slightly important, $1=$ not important). The residents perceived that the training updated their teaching skills $3.64 \pm 0.50$ rated on Likert Scale 1-4 (4=Strongly agree, $3=$ Fairly agree, $2=$ Slightly agree, $1=$ Not agree). The residents mentioned that training was interactive, participatory and friendly and demonstration of clinical skills through video was significant.
\end{abstract}

Conclusion: The findings of present study suggest positive perception of the residents on this short-term training to train resident as a teacher.

Keywords: Feedback; Perception; Residents; Teachers; Training

\section{Introduction}

Residents of health professions education during their training undertake several duties of varied nature; one of the important among them is teaching. This is one of the essential responsibilities. They educate junior residents, interns, medical students and patient and their family/caretaker too [1,2].

Residents can become effective clinical teacher as they occupy distinctive position during their residency in the hospital clinical settings. They are intensely involved in the patient care and very well understand the needs of learning and needs of students too [2]. Encounter of medical students and interns is comparably more with the residents than faculty. Medical students too state that they learn from the residents [2].

It is observed that residents are interested in teaching, spend $20 \%$ of their time in teaching and enjoy teaching too but are not trained as teacher in most of the medical schools [3,4]. Developed countries have recognized the need of training program "Resident as a Teacher", developed curriculum for training and continue to train residents but majority of the schools in developing and underdeveloped countries including Nepal is far behind in this aspect $[4,5]$. 
With the objectives to foster the capacity of resident as an educator/teacher and to enhance their skills in clinical teaching, a one day "Training to train resident as a clinical teacher" was conducted in March 30, 2019 at Universal College of Medical Sciences (UCMS) Teaching Hospital (TH) Bhairahawa Nepal. The objective of this study was to take feedback of participant residents and assess how they perceive the training at level-I of Kirkpatrick model of evaluation.

\section{Methodology}

A one day "Training to train resident as a clinical teacher" was conducted in March 30, 2019 at Universal College of Medical Sciences (UCMS) Teaching Hospital (TH), Bhairahawa, Nepal by lead author as a resource person.

Fourteen residents from clinical departments of UCMS-TH (2 each from department of Internal Medicine, General Surgery, Obstetrics \& Gynecology, Pediatrics and Orthopedics and one each from Anaesthesia, ENT, Psychiatry and Emergency Department participated in training.

There were two one-hour session on "Knows about adult learning principles" and "Knows about Learning Domains" and six hours session was on "How to be an effective clinical teacher". This session covered sub-sessions "Overview on Teaching Learning methods", "Five-Steps "Micro-skills" Model of Clinical Teaching", "Bedside Teaching”, “Teaching Procedures”, “Debriefing \& Feedback”, and "Lesson Planning for Clinical Teaching". The session on "Knows about adult learning principles" and sub-session on "Overview on Teaching Learning methods" facilitated by third and fourth authors respectively. While session on "Knows about Learning Domains" and five of six sub-sessions "How to be an effective clinical teacher "by first author.

The objective of this study was to take feedback of the participant residents and assess how they perceive the training at level-I of Kirkpatrick model of evaluation. Kirkpatrick model of evaluation has four levels:

Level I: Reaction; Level 2A: Learning-change in attitude; Level 2B: Learning-modification of knowledge and skills; Level 3: Behavior-change in behavior; Level 4A: Results: change in the system or organizational practice and Level 4B: Results-change among the participants' students and peers [6].

At the end of training workshop, feedback of the participant residents was taken on the valid semi-structured questionnaire comprised of four parts.

\section{Part A. Demographic information}

Info was taken on age in years, sex and year of graduation.

\section{Part B. Overall feedback on training}

This part contained two close ended questions; one was on rating training on scale 1-10 (1=poor, 10=excellent) for usefulness, content, relevance, facilitation and training as overall; while another was whether training updated your teaching skills on Likert Scale 1-4 (4=Strongly agree, 3=Fairly agree, 2=Slightly agree, $1=$ Not agree).

\section{Part C. Feedback on specific sessions}

This part covered four closed ended questions. The first two questions were on rating sessions "knows about adult learning principles" and "Knows about learning domains" conducted in training on scale 1-10 (1=poor, $10=$ excellent); while other two questions were on session "How to be an effective clinical teacher, and sub-session "How to plan lesson for teaching" rated on Likert scale 1-4 (4=extremely Important, 3=moderately important, 2=slightly important, 1=not important).

\section{Part D. Feedback for improvement}

This part had three open ended questions; one was on good points/strengths of training, second on areas for improvement and third for additional comments.

The informed consent was taken from the participants and ethical approval was obtained from institutional review committee of UCMS.

The data collected was checked for completeness, accuracy and consistency. It was entered in SPSS version 21 for analysis. Descriptive analysis was done; the frequency, mean and standard deviation were computed.

\section{Results}

\section{Part A- Demographic information}

The age of the participant resident was 29.2101.25 years (range 27-32 years); 08 (57\%) were males and 06 (43\%) females. Their year of graduation were between 2012-2015

\section{Part B- Overall feedback on training workshop}

\begin{tabular}{|c|c|}
\hline $\begin{array}{c}\text { Table 1: Rating of the participant "Training to train resident as a teach- } \\
\text { er". }\end{array}$ & Rating (Mean \pm SD) \\
\hline Item & $9.21 \pm 1.05$ \\
\hline Usefulness (Scale 1-10) & $9.07 \pm 1.00$ \\
\hline Relevance of session (Scale 1-10) & $9.29 \pm 0.82$ \\
\hline Facilitation (Scale 1-10) & $9.50 \pm 0.85$ \\
\hline Overall (Scale 1-10) & $9.29 \pm 0.82$ \\
\hline
\end{tabular}

The participant rated the "Training to train resident as a teacher" on scale 1-10 (1=poor, $10=$ excellent); the rating was notable (Table 1).

Participants response on "Has this training updated your teaching skill?" was $3.64 \pm 0.50$ rated on Likert Scale 1-4. (4=Strongly agree, 3=Fairly agree, 2=Slightly agree, 1=Not agree). It was noteworthy.

\section{Part C- Feedback on specific sessions}

The rating of the participants on specific session/s conducted in "Training to train resident as a teacher" was also remarkable (Table 2). 
Table 2: Rating of the participants on specific sessions conducted in "Training to train resident as a teacher".

\begin{tabular}{|c|c|}
\hline Item & $\begin{array}{c}\text { Rating } \\
\text { (Mean } \pm \\
\text { SD) }\end{array}$ \\
\hline $\begin{array}{c}\text { Session on "knows about adult learning principles" con- } \\
\text { ducted in training rated on scale 1-10 (1=poor, 10=excel- } \\
\text { lent) }\end{array}$ & $8.71 \pm 1.25$ \\
\hline $\begin{array}{c}\text { Session on "learning domains" conducted in training rated } \\
\text { on scale 1-10 (1=poor, 10=excellent) }\end{array}$ & $8.93 \pm 1.41$ \\
\hline $\begin{array}{c}\text { *Sessions on "How to be an effective clinical teacher" con- } \\
\text { ducted in training rated on Likert scale 1-4 }\end{array}$ & $3.79 \pm 0.43$ \\
\hline $\begin{array}{c}\text { *Sub-session on "How to plan lesson for teaching" conduct- } \\
\text { ed in training rated on Likert scale 1-4 }\end{array}$ & $3.79 \pm 0.43$ \\
\hline
\end{tabular}

*(4=extremely important, 3=moderately important, 2=slightly important, 1=not important)

Part D- Feedback for improvement

Good points/strengths of training appreciable (Table 3)

Table 3

\begin{tabular}{|c|c|}
\hline Good points/strengths & $\begin{array}{l}\text { No of partici- } \\
\text { pants }\end{array}$ \\
\hline Training was interactive, participatory and friendly & 5 \\
\hline $\begin{array}{l}\text { Demonstration of clinical skills through video was } \\
\text { significant }\end{array}$ & 5 \\
\hline Two-way communication & 3 \\
\hline $\begin{array}{l}\text { Five steps micro skills session played an important } \\
\text { role }\end{array}$ & 3 \\
\hline Effective delivery of knowledge and skills & 3 \\
\hline Systematic way of approach to teaching & 2 \\
\hline Session on Teaching learning methods & 2 \\
\hline Session on Lesson planning for clinical teaching & 2 \\
\hline How to teach others as a teacher & 2 \\
\hline Session on Learning domains & 2 \\
\hline Good Resource persons & 2 \\
\hline How to approach to patient & 1 \\
\hline Session on Teaching clinical skills & 1 \\
\hline
\end{tabular}

Areas of improvement: Five participants suggested to expand the duration of training; could be for 2-3 days to grasp more information on the subject of teaching. Two participants stated, "It would have been more fruitful if bedside clinical demonstration was done".
Additional comments: Training was a great opportunity for learning. It was fruitful, helpful and effective. It has created curiosity for learning. Such training must be organized on regular basis.

\section{Discussion}

Residents are adult learners and play multiple roles in hospital settings such as postgraduate student, member of healthcare team, researcher, educator or teacher [4]. Their role as teacher and its impact on learning of junior residents, interns, students, quality care of the patients and their own learning is acknowledged $[1,2,4,6]$ It is true to teach is to learn twice [7].

The feedback of the participant residents on one day "Training to train resident as a teacher" and their perception at Kirkpatrick Evaluation Model level-I was noticeable. The rating of the participants on training on scale 1-10 for usefulness was $9.21 \pm 1.05$, content $9.07 \pm 1.00$, relevance $9.29 \pm 0.82$ ), facilitation $9.50 \pm 0.85$, and overall $9.29 \pm 0.82$. Their rating on specific session/s "knows about adult learning principles" were $8.71 \pm 1.25$ and "learning domains" $8.93 \pm 1.41$ rated on scale 1-10 while on session on "How to be effective clinical teacher" $3.79 \pm 0.43$ and sub-session on "How to plan lesson for teaching" $3.79 \pm 0.43$ rated on Likert Scale $1-4 *(4=$ extremely important, $3=$ moderately important, $2=$ slightly important, $1=$ not important). The residents perceived that training updated their teaching skills $3.64 \pm 0.50$ rated on Likert Scale 1-4 (4=strongly agree, 1 =disagree).

More than one third residents mentioned that training was interactive, participatory and friendly and demonstration of clinical skills through video was significant while more than one fifth cited "two-way communication", "five steps micro skills sessions and effective delivery of knowledge and skills" among strengths of training. Residents suggested to increase the duration of training as to comprehend more information on the subject of teaching. They quoted training was a great opportunity for learning and created curiosity for learning.

Various studies support train resident as a teacher. This educational intervention update teaching skills of the residents and enhances their capacity and confidence in teaching $[1,2,4,8]$.

The study is limited by small sample size of the participants and focused on the perception of the participants. The findings of present study suggest positive perception of the residents on this short-term training to train resident as a teacher.

\section{Conflict of Interest}

No

\section{Acknowledgement}

We appreciate 2nd year MD/MS/MDS postgraduate residents of various departments of Universal College of Medical Sciences, Bhairahawa, Nepal for their vountry participation in this study.

\section{References}

1. Wachtel JK, Greenberg MR, Smith AB, Weaver KR, Kane BG (2013) Residents as Teachers: Residents' Perceptions Before and After Receiving Instruction in Clinical Teaching. J Am Osteopath Assoc 113(1): 23-33. 
2. Ostapchuk M, Patel PD, Miller KH, Ziegler CH, Greenberg RB, et al. (2010) Improving residents' teaching skills: A program evaluation of residents as teachers' course. Med Teach 32(2): e49-e56.

3. Ng VK, Burke CA, Narula A (2013) Residents as teachers: Survey of Canadian family medicine residents. Can Fam Physician 59(9): e421-e427.

4. Sánchez Mendiola M, Graue Wiechers EL, Ruiz Pérez LC, García Durán R, Durante Montiel I (2010) The resident-as-teacher educational challenge: a needs assessment survey at the National Autonomous University of Mexico Faculty of Medicine. BMC Med Educ 10: 17.

5. Al Achkar M, Hanauer M, Morrison E H, Davies M K, Robert C Oh (2017) Changing trends in residents-as-teachers across graduate medical education. Adv Med Educ Pract 8: 299-306.
6. Bree K K, Whicker S A, Fromme H B, Paik S, Greenberg L (2014) Residents-as-Teachers Publications: What Can Programs Learn from the Literature When Starting a New or Refining an Established Curriculum? J Grad Med Educ 6(2): 237-248.

7. Weiss V, Needlman R (1998) To teach is to learn twice: resident teachers learn more. Arch Pediatr Adolesc Med 152(2): 190-192.

8. Hosein Nejad H, Bagherabadi M, Sistani AR, Dargahi H (2017) Effectiveness of resident as teacher curriculum in preparing emergency medicine residents for their teaching role. J Adv Med Educ Prof 5(1): 2125. 